\title{
Heat Exchangers for Condensation and Evaporation Applications Operating in a Low Pressure Atmosphere
}

\author{
Petr Kracík ${ }^{1}$, Jiří Pospíšil ${ }^{1}$, Ladislav Šnajdárek ${ }^{1}$ \\ ${ }^{1}$ Brno University of Technology, FME, Department of Power Engineering, \\ Technická 2896/2, 61669 Brno, Czech Republic
}

Correspondence to: kracik@fme.vutbr.cz

\begin{abstract}
This paper presents a state-of-the-art study of a heat transfer process in liquid spraying heat exchangers placed in a vacuum chamber. The experimental case studied here describes the behavior of a falling film evaporation and condensation mode on horizontal tube bundles. The study aims to obtain the heat transfer coefficient and its correlations by means of a mathematical model.
\end{abstract}

Keywords: liquid spraying, heat exchangers, vacuum chamber.

\section{Introduction}

The use of cooling increases year by year, not only in the food, chemical and engineering industries, but especially in shopping centers, in office buildings and in homes. Cold compressor cooling systems, which consume a lot of energy, are the most widely produced systems. An alternative way of cooling that consumes approximately one-fifth of the energy is by using absorption units. The absorption cycle is supplied directly by heat from gas burners, or is indirectly generated by power plants in the form of waste heat. The use of waste heat leads primarily to fuel saving. If the cold that is produced is used to increase thermal comfort in the summer season, the use of waste heat can spread heat production more equally throughout the year. This can result in a stable output of power units throughout the year, increasing the reliability and therefore the lifetime of power units.

The heat exchanger is an essential component of the absorption cycle that provides optimum heat transfer. In this paper, the authors attempt to determine the surface heat transfer coefficient of a spray-water cooled exchanger located in a vacuum chamber. The vacuum is generated by a rotary vane vacuum pump. This basic research follows a study of the heat transfer coefficient on a tube bundle at atmospheric pressure, which is being carried out in the Dept. of Power Engineering at the Energy Institute of the Faculty of Mechanical Engineering of the Technical University in Brno.

\section{Description of the vacuum apparatus}

The chamber is a cylindrical airtight vessel with three visors, in which a tube bundle is placed. The chamber is connected to three closed loops. Two of these loops are designed for pressure up to $1.0 \mathrm{MPa}$, and they are used for transporting a cooling/heating fluid (depending on the type of experiment - condensation/evaporation). The third loop is used for transporting a liquid spray. Each loop is equipped with a pump, a regulation valve, a flow meter and a plate heat exchanger. The plate heat exchanger can be connected to a boiler filled with hot water, for heating the liquid or with cold water in the case of cooling. Each of the pressure loops is also equipped with an expansion vessel, which serves to compensate the pressure differences, and with a safety valve that releases the liquid when there is overpressure. For visual control, each of the loops is equipped with a pressure gauge and a thermometer.

The temperature condition of the media in the individual loops is measured by thermocouples at the inlets or outlets of the container. For a more accurate approximation of the heat stratification in the tube bundle, there are four thermocouples: two for each loop that is not transporting liquid spray.

The mounting plate for the tube bundle is divided into two halves. Each half has been drilled with different spacing of the holes to provide large variability of the tube arrangements. The tube bundle is composed of copper tubes and sprinkler pipes, one over each vertical row of copper tubes. The copper tubes are $12.0 \mathrm{~mm}$ in 


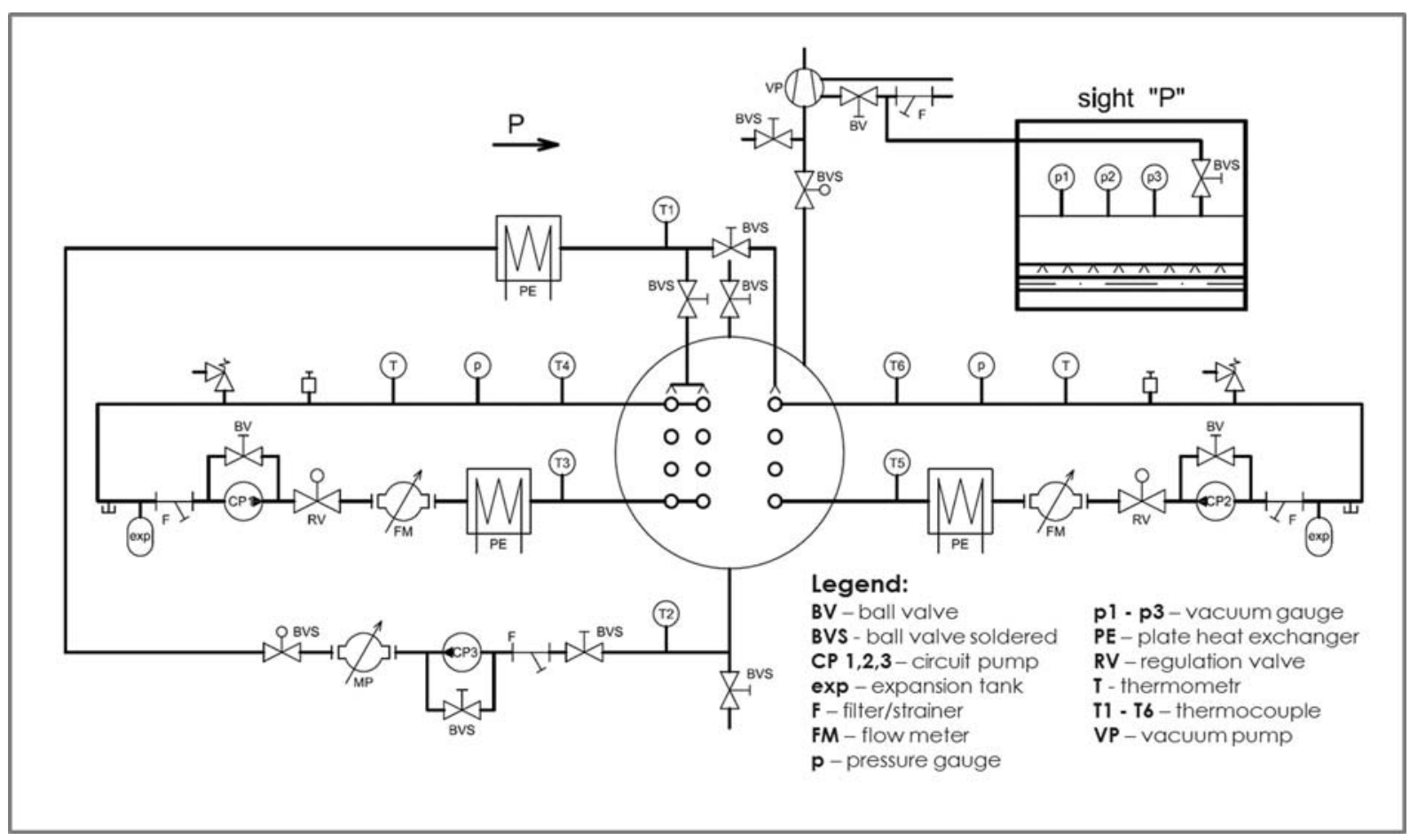

Figure 1: Diagram of the vacuum apparatus

diameter. The sprinkler pipe is a tube $940.0 \mathrm{~mm}$ in length, with $9.2 \mathrm{~mm}$ spacing of the sprinkling holes $1.0 \mathrm{~mm}$ in diameter.

The pressure in the chamber is measured by three pressure gauges. The first utilizes mercury, and is used for visual inspection. The second is a digital gauge, and it can measure the entire desired pressure range. The third is a digital vacuum gauge, with an absolute pressure range of $0 \mathrm{kPa}$ to $25 \mathrm{kPa}$, and serves for accurate low-pressure measurements.

\section{Mathematical description}

Under the conservation of energy, the heat balance between the right-closed pressurized loop (marked with suffix 'B') and the under-pressured loop (marked with suffix ' $V$ ') must be guaranteed:

provided that:

$$
\begin{aligned}
\dot{Q}_{5}+\dot{Q}_{1} & =\dot{Q}_{6}+\dot{Q}_{2}+\Delta \dot{Q}_{56}+\Delta \dot{Q}_{12} \\
& \Rightarrow \quad \dot{Q}_{B}=\dot{Q}_{6}-\dot{Q}_{5} \quad[\mathrm{~W}] \\
& \Rightarrow \quad \dot{Q}_{V}=\dot{Q}_{1}-\dot{Q}_{2} \quad[\mathrm{~W}]
\end{aligned}
$$

The heat transfer red through the copper tube wall:

$$
\dot{Q}_{S}=\dot{Q}_{B}+\Delta \dot{Q}_{56}=\dot{Q}_{V}-\Delta \dot{Q}_{12} \quad[\mathrm{~W}]
$$

\section{- derivation equations of heat transfer through a circular wall}

The heat passage of the wall is composed of conduction, convection and also radiation. At lower temperatures, the heat transmitted by radiation is negligible, and is therefore not considered in the calculation. The calculation is based on Newton's principle of heat transfer and the Fourier heat conduction principle, provided there is a parallel arrangement of pipes. Walls do not contain internal sources, and the heat flow is in the radial direction relative to the tube.

The heat passage is determined by substituting into the general equations and integrating them

$$
\dot{Q}_{S}=\frac{2 \cdot \pi \cdot n \cdot L\left(t_{\text {out }}-t_{\text {in }}\right)}{\frac{1}{H_{\text {in }} \cdot r_{\text {in }}}+\frac{1}{\lambda_{S}} \cdot\left[\ln \left(\frac{r_{\text {in }}}{r_{\text {out }}}\right)\right]+\frac{1}{H_{\text {out }} \cdot r_{\text {out }}}}
$$




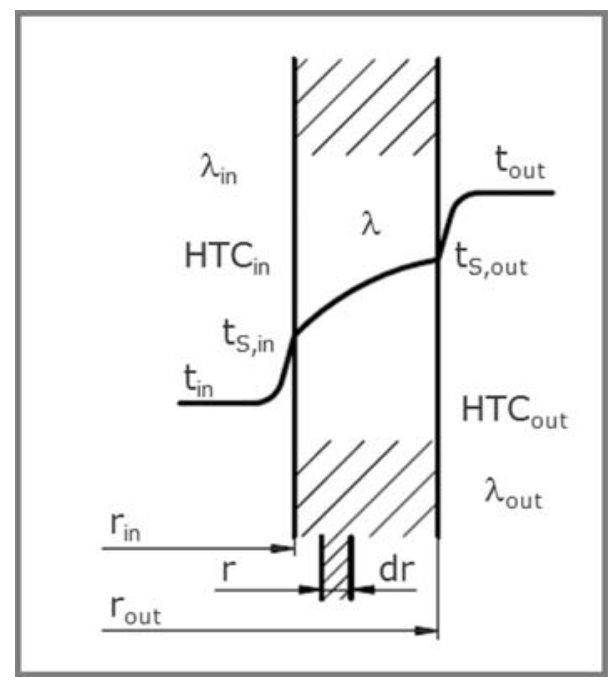

Figure 2: Sign parameters for calculating the heat transfer

Where selected members of the equation express the heat transfer coefficient:

$$
u_{S}=\frac{2 \cdot \pi}{\frac{1}{H_{\text {in }} \cdot r_{\text {in }}}+\frac{1}{\lambda_{S}} \cdot\left[\ln \left(\frac{r_{\text {in }}}{r_{\text {out }}}\right)\right]+\frac{1}{H_{\text {out }} \cdot r_{\text {out }}}} \quad\left[\mathrm{W} \cdot \mathrm{m}^{-1} \cdot \mathrm{K}^{-1}\right]
$$

The heat exchangers do not have a balanced temperature gradient at the inlet and outlet refrigerant. This is therefore replaced by the meanlogarithmic temperature gradient. Thus the final equation for the heat passage circular wall in the radial direction is:

$$
\dot{Q}_{S}=k_{S} \cdot n \cdot L \cdot \Delta T_{l n} \quad[\mathrm{~W}]
$$

- calculation of the heat transfer on the outside of the tube

The heat transfer coefficient on the outside of the tube is derived from the heat passage equation:

$$
H_{\text {out }}=\frac{1}{2 \cdot \pi \cdot r_{\text {out }} \cdot\left[\frac{1}{k_{S}}-\frac{1}{2 \cdot \pi \cdot H_{\text {in }} \cdot r_{\text {in }}}-\frac{1}{2 \cdot \pi \cdot \lambda_{S}} \cdot \ln \left(\frac{r_{\text {in }}}{r_{\text {out }}}\right)\right]} \quad\left[\mathrm{W} \cdot \mathrm{m}^{-2} \cdot \mathrm{K}^{-1}\right]
$$

Equal (5) and (8) must be valid for the heat passage equations, which results in the heat transfer coefficient:

$$
\begin{aligned}
\dot{Q}_{S} & \left.=\dot{Q}_{B}+\Delta \dot{Q}_{56}=k_{S} \cdot n \cdot L \cdot \Delta T_{l n} \quad \mathrm{~W}\right] \\
k_{S} & =\frac{\dot{Q}_{S}}{n \cdot L \cdot \Delta T_{l n}}=\frac{\dot{V}_{V} \cdot \rho_{V}\left(p_{v} ; \bar{T}\right) \cdot c_{p}\left(p_{v} ; \bar{T}\right) \cdot\left(T_{1}-T_{2}\right)}{n \cdot L \cdot \Delta T_{l n}} \quad\left[\mathrm{~W} \cdot \mathrm{m}^{-1} \cdot \mathrm{K}^{-1}\right]
\end{aligned}
$$

The investigated apparatus is among loops "A" and "V", and the logarithmic temperature gradient is expressed as:

$$
\Delta T_{l n}=\frac{\Delta T_{1}-\Delta T_{2}}{\ln \left(\frac{\Delta T_{1}}{\Delta T_{2}}\right)}=\frac{\left(T_{1}-T_{6}\right)-\left(T_{2}-T_{5}\right)}{\ln \left(\frac{T_{1}-T_{6}}{T_{2}-T_{5}}\right)} \quad[\mathrm{K}]
$$

The last unknown in equation (9) is the coefficient of heat transfer inside the tube. It can be calculated using the Nusselt number, which is defined as the ratio of the heat transfer by convection and by conduction. $[1,2]$

$$
N u=\frac{H_{\text {out }} \cdot L}{\lambda} \Rightarrow H_{\text {out } 1}=\frac{N u_{D} \cdot \lambda_{\text {in }}}{d_{\text {in }}} \quad\left[\mathrm{W} \cdot \mathrm{m}^{-2} \cdot \mathrm{K}^{-1}\right]
$$

The following criteria are accepted for calculating the Nusselt number:

1. The Reynolds number for fully developed turbulent flow is:

$$
R e=\frac{w_{i n} \cdot d_{i n}}{\nu} \geq 10000
$$


2. The Prandtl number ranges between:

$$
0.6 \leq\left(\operatorname{Pr}=\frac{\nu}{a}\right) \leq 160
$$

3. The ratio of the length to its diameter pipe:

$$
\frac{L}{d_{1}} \geq 10
$$

The Nusselt number is stated as:

$$
N u_{D}=0.023 \cdot R e_{D}^{0.8} \cdot \operatorname{Pr}^{n}
$$

where coefficient " $n$ " (in the case of heating fluid in the pipe) is equal to $0.4[-]$ and in the case of cooling fluid in the pipe, it is equal to $0.3[-]$. The fluid velocity is calculated from the volume flow as:

$$
\dot{V}_{B}=S_{i n} \cdot w_{i n} \Rightarrow w_{i n}=\frac{4 \cdot \dot{V}_{B}}{\pi \cdot d_{i n}}
$$

- comparison between the falling-film mode map and data in the literature

The Reynolds number expressed for the jet-droplet mode [4]:

$$
R e=0.084 \cdot G a_{\bmod }^{0.302} \quad[-]
$$

The Galileo number is stated as a reciprocal Kapitza number:

$$
G a_{\mathrm{mod}}=\frac{1}{K a}=\frac{\rho \cdot \sigma^{3}}{\mu^{4} \cdot g}
$$

We compare the experimentally obtained values from the vacuum apparatus with the values obtained by Jacobi and $\mathrm{Hu}$ [4] using the criteria number (19), (20). This data was obtained from atmospheric apparatus with a comparable configuration of the heat exchanger, as shown in Figure 3.

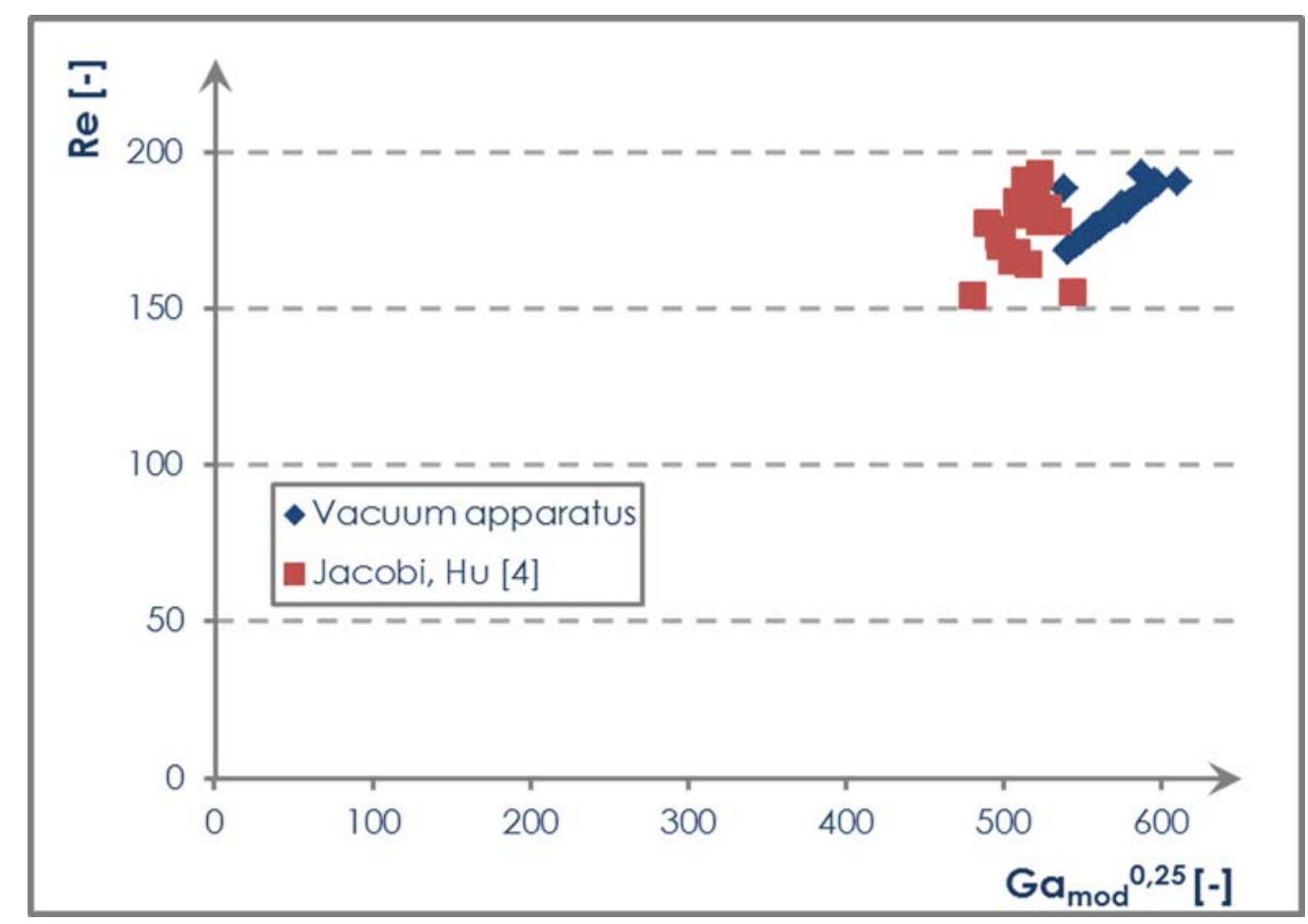

Figure 3: Experimental results for the jet-droplet transition mode 


\section{Evaluation of measured data}

The measurements of temperature, pressure and other variables that are required for calculating any coefficient in the equations above are obtained with inaccuracies. The values are always inaccurate, due to the environment, the selected measuring method, or the condition of the measuring devices. There is always some tolerance within which the final value is spread. Before we start evaluating the measured data, we have to determine the limits from the calibration measurements. The limits determined by the quadratic sum of the type A uncertainties represents a statistical evaluation of the measured data set and the type B uncertainty of which is determined by the instrument manufacturer or calibration of the measuring devices. The uncertainty of the indirectly measured physical quantities derived from the measured data set is coupled with a similar equation. The T-type enclosed thermocouples that were used, with an ungrounded end and with increased accuracy, were calibrated in an Omega CL1000 dry block probe calibrator, which controls the temperature set by PID regulation with accuracy of $0.15^{\circ} \mathrm{C}$.

Due to the calibration curve, we decided to use a single error for all thermocouples which consists of the measured maximum peak, or the minimum peak (which achieved a maximum statistical error of $0.006{ }^{\circ} \mathrm{C}$ ) and dry block probe calibrator errors. Figure 4 plots the calibration curves of the T-thermocouples used in the measuring loops with factory inaccuracies $u_{B, T}$ (19)

$$
u_{B, T}= \pm 0.65 \quad\left[{ }^{\circ} \mathrm{C}\right]
$$

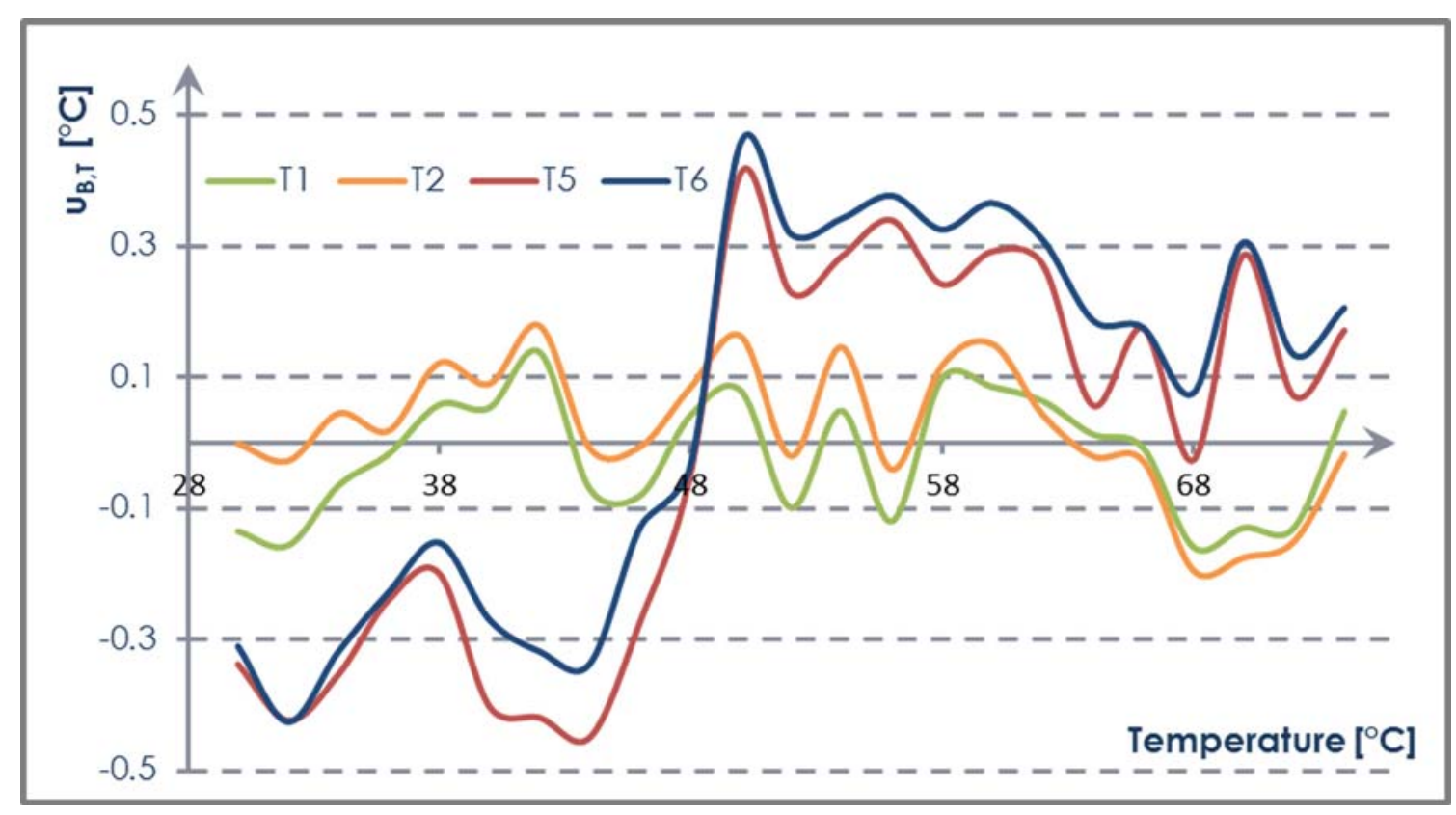

Figure 4: Segment of the calibration curve using thermocouples

The vacuum (under-pressure) was measured using a TED 6 digital gauge with pressure inaccuracy $0.5 \%$ of the measured absolute pressure range:

$$
u_{B, p_{v}}= \pm 0.005 \cdot(0 \ldots 100)= \pm 0.50 \quad[\mathrm{kPa}]
$$

The flow rates and the spraying loop were measured using a FLOMAG3000 inductive flowmeter within accuracies:

$$
u_{B, V}= \pm 0.003 \cdot(0.30 .67)= \pm 0.092 \quad\left[1 \cdot \mathrm{min}^{-1}\right]
$$

Figure 5 plots the investigated heat transfer coefficients on the outside of the tube.

The measurements were performed for three levels of absolute pressure: $6.2 \mathrm{kPa}, 19.2 \mathrm{kPa}$ and $30.2 \mathrm{kPa}$. The derived points were interspersed with the exponential curve that best described the increasing heat transfer coefficient trend, with an increasing flow rate in spite of the fact that a lower correlation was still sufficient at a pressure level of $6.2 \mathrm{kPa}$. 


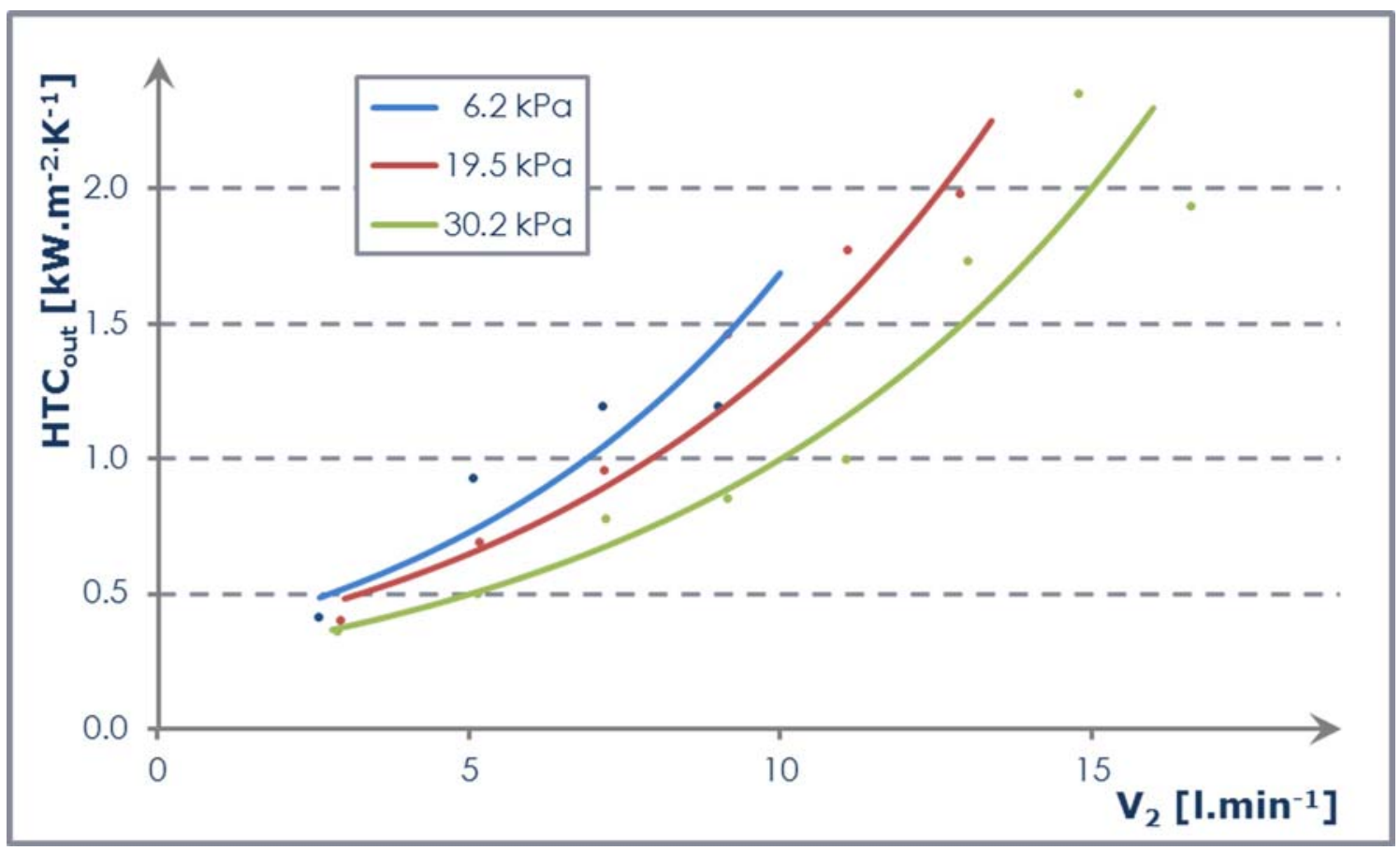

Figure 5: Heat transfer coefficients on the outside of the tube

\section{Conclusion}

On a vacuum compiled apparatus, we measured the temperature, pressure and flow meter values, from which the heat transfer coefficient was deduced. The increasing heat transfer coefficient trend on the outside of the tube depends on the ambient pressure reduction that is achieved. This trend corresponds to the theory and to the current state of knowledge on spraying exchangers. In the vacuum apparatus will continue implementing to the influence of surface treatment tubes and design to increase the heat transfer coefficient.

\section{Acknowledgement}

This work has been financially supported by the Czech Science Foundation under the Grant P101/10/1669.

\section{References}

[1] Incropera, F. P., Dewittl, D. P., Bergman, T., Lavine, A.: Fundamentals of Heat and Mass Transfer, $6^{\text {th }}$ Edition, 2007, Hardcover, 1024 p. ISBN 978-0-471-45728-2.

[2] Jícha, M.: Přenos tepla a látky, Brno. CERM, 2001, 160 p. ISBN 80-214-2029-4.

[3] Karpíšek, Z.: Matematika IV: statistika a pravděpodobnost. $3^{\mathrm{rd}}$, Brno : CERM, 2007, 170 p. ISBN 978-802-1433-809.

[4] Jacoby, A., Hu, X.: The Intertube Falling-Film Modes: Transition, Hysteresis, and Effects on Heat Transfer, Urbana, IL 61801, (217) 333-3115, 1995. 